\title{
INFLUENCE OF COLD ROLLING ON THE MECHANICAL AND TECHNOLOGICAL PROPERTIES OF AHSS STEEL GRADES*
}

\author{
Michael Breuer ${ }^{1}$ \\ Michael Degner ${ }^{2}$ \\ Gerald Bader ${ }^{3}$ \\ Wolfgang Bleck ${ }^{4}$ \\ Francisco Morganti ${ }^{5}$
}

\begin{abstract}
This report gives in the first part the metallurgical basics for the production of AHSS grades in integrated steel plants starting at the melt shop and ending at the annealing lines of the cold mill. The corresponding process and plant technologies in each production step with its specifics and rules are explained. In the second part by way of example the practical requirements for TRIP 780 steel grade are highlighted like a recipe for process control in the steel plant, hot and cold rolling mill, annealing line and finally skin pass mill. Measuring of mechanical technological properties on samples shows that the specifications according to DIN EN 10268 are fulfilled.
\end{abstract}

Keywords: Hot Strip Mill, Cold Rolling Mill, Annealing Line, Strip Temperature, Thickness Reduction.

1 Dr.-Ing., Head of Product Development / Concept Engineering / Technological Commissioning, Flat Rolling Plants, SMS group, Hilchenbach, Germany

2 Dr.-Ing., Technology EngineerProduct Development / Concept Engineering / Technological Commissioning, Flat Rolling Plants, SMS group, Hilchenbach, Germany

3 Senior Process Expert Cold Rolling Mills on behalf of SMS group GmbH Flat Rolling Plants, Hilchenbach, Germany

4 Univ. - Prof. Dr.-Ing., Chairand Head of Department of Ferrous Metallurgy, RWTH Aachen, Aachen, Germany.

5 Mechanical Engineer, Executive Vice President, Order Execution, SMS group Metalurgia do Brasil Ltda. Vespasiano, MG, Brazil.. 


\section{INTRODUCTION}

This report describes the influence of cold rolling of steel materials in tandem mills on the establishment of the mechanical and technological properties of the finished product. The metallurgical principles and relationships are presented and discussed.

\section{DEFINITION OF TERMS AND PRINCIPLES [1, 2]}

The abbreviation AHSS means Advanced High Strength Steel and designates modern, high-strength, unalloyed steel grades.

AHSS steels are used predominantly in automotive engineering. Here they are employed for safety-relevant components to absorb elastic (deformation) energy. At the same time, the thinner steel sheets make the car bodies lighter and stronger, contributing to both weight saving and crashworthiness. The development of these steel grades will ultimately also enable the future target emissions per driven kilometer (95 g CO2/km from 2020 for Europe, currently $130 \mathrm{~g} \mathrm{CO} / \mathrm{km}$ ) already adopted by the legislators to be achieved.

The group of AHSS steels includes dual-phase, multi-phase, ultra-high-strength complex phase and bake-hardening steel. TRIP steel (Transformation Induced Plasticity) and TWIP steel (Twinning Induced Plasticity) play special roles within this group. TRIP and TWIP steels change their strength during forming. They are furthermore characterized by martensitic and bainitic microstructure fractions, giving them high strength with good shape ability.

The properties of AHSS grades are controlled not only by the setting of the chemical composition in the melt shop, but also by the process control in the hot strip mill with the setting of the final rolling temperature and the coiling temperature, via the cooling rates on the exit roller table and by the temperature control in the downstream plants of the strip treatment line in the cold rolling mill.

The rolling process in tandem mills, generally with 5 stands but also with 6 stands in 4-high or 6-high configuration, serves the purpose of the further reduction of the strip thickness necessary for the end user's application process and has no primary influence on the mechanical characteristics. The degree of reduction in the tandem mill with the resulting material hardening, however, has a secondary influence on the setting of the process control on the continuous annealing lines (CALs) with integrated post-rolling on the skin pass mill (SPM).

The setting of rolling, cooling and annealing parameters with a view to continuous process control, from melt shop through to the annealing units for the strip treatment and finishing are of fundamental interest to both plant operators and plant manufacturers.

The mechanical and technological properties (strength and ductility) of metallic materials are predominantly determined by the type and formation of the microstructure. The microstructure can be influenced by forming processes and heat treatment; the thermomechanical treatment in hot strip mills (HSM) represents a combination of forming and heat treatment [1]. 
In the production chain of flat products after setting of the chemical composition in the melt shop, the continuous cast slab initially has a coarse cast microstructure with unfavorable mechanical properties. All technical processes for the production of intermediates therefore comprise a hot forming stage which serves the purpose of setting the geometry within given tolerances, compacting and transformation of the cast microstructure into a wrought microstructure and the influencing of the microstructure in order to set the utilization properties [1].

The purposes of hot forming are [1]:

- Shaping with defined dimensional tolerances.

- Compaction of the cast microstructure in order to improve the inner and outer condition of the rolled stock. A degree of deformation of approx. $\varphi=0.8$ has proved expedient for closing pores and achieving a high level of breaking elongation.

- Setting of the application microstructure and the demanded mechanical properties. Important parameters for influencing the microstructure are the temperature/time forming cycle and the cooling rates, particularly during the phase transformations.

Among the AHSS grades, a distinction is made between three groups according to their alloying elements and the start of their industrial application. The conventional HSS (High Strength Steel) grades, such as the micro-alloyed or bake-hardening grades, have been produced since the 1980s.

The first generation of AHSS grades (AHSS 1.G) arrived from 1990 with a microstructure comprising at least two different phase fractions. This led to an increase in the yield stress without impairing the toughness properties. These dual or multi-phase steels offer the potential of a combination of modified yield points with corresponding toughness thanks to the coexistence of the different phases. They lead to differing behavior under mechanical load and interact mutually with one another. In most steel grades, the matrix contains bcc ferrite, while the percentage of the other phases increases. The dual-phase steels, for example, contain $30 \% \mathrm{v} / \mathrm{v}$ bct martensitic or TRIP steels $15 \% \mathrm{v} / \mathrm{v}$ residual austenite.

This change from the bcc matrix structure to an fcc matrix allows the toughness to be increased with a constant or even higher yield stress. The alloying level required for this ranges up to $20 \% \mathrm{w} / \mathrm{w}$ for a pure austenite microstructure or more than $10 \% \mathrm{w} / \mathrm{w}$ for a mixed microstructure comprising austenite and ferrite/martensitic. This means that the individual alloying element is no longer statistically distributed, and the complete microstructure is no longer in solution. The interaction between the alloying elements is the primary control parameter for setting and controlling the mechanical properties. The microstructure or individual phase fractions within the microstructure continue to be unstable under mechanical load, leading to stress-induced transformations. These transformations improve the shapeability by increasing the uniform hardening. Alloyed manganese steels or multi-phase steels with a high austenitic volume can be divided into three groups according to their plastic deformation behavior: (1) TRIP steel, (2) TWIP steel and (3) SIP steel. These steels are the 2 nd generation AHSS grades and have been developed since 2000. 
Typical ranges of the mechanical properties of three steel grades are summarized in Figure 1. The microstructure consists of different phase fractions, depending on the $\mathrm{Mn}$ content. It is characterized by the fcc austenite, hcp martensitic, bct martensitic, twin austenite and bcc ferrite volumes. The mechanical properties of the alloys depend on the initial microstructure and the changes during forming. The $\gamma-\varepsilon$ and $\varepsilon-\alpha^{\prime}$ transformation temperatures decrease with increasing Mn content.



Figure 1: Groups of higher-strength materials for automotive engineering with the corresponding mechanical properties [2]

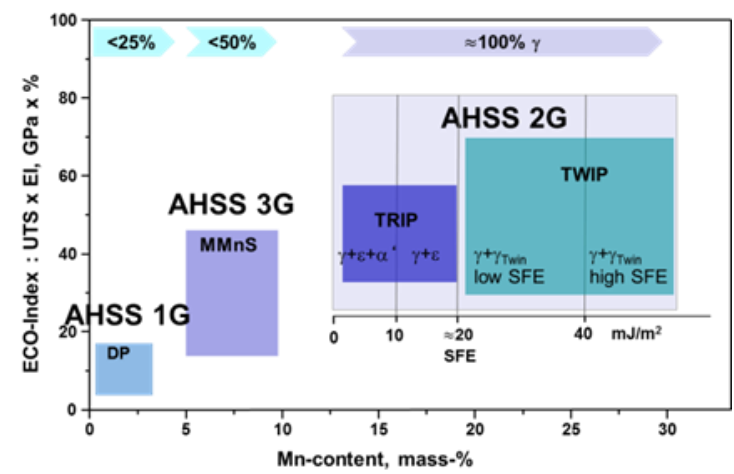

Figure 2: Groups of higher-strength materials for automotive engineering. Steel grades with ECO index and Mn content and their austenite phase fractions [2]

The alloy concept of the 3rd generation AHSS grades (AHSS 3.G, since 2010) comprises $5-7 \% \mathrm{w} / \mathrm{w} \mathrm{Mn}$ with minor additions of $\mathrm{Al}$ and $\mathrm{Si}$ of less than $2 \% \mathrm{w} / \mathrm{w}$. These lower alloying fractions have a positive effect on the costs of the process control during casting and rolling and on the coating properties of the finished product. With the variety of chemical alloys it is possible to select the production steps in such a way that a microstructure is formed with a sub-micron ferrite content coupled with high ferrite content. This is then transformed into martensitic by the TRIP effect. This means that it is possible to set a multi-phase microstructure comprising ferrite, martensitic and austenite with the desired mechanical and technological properties. The first trials into the production and processing resulted in upper tensile strength (UTS) values of more than $1 \mathrm{GPa}$ with a total elongation (TEL) of more than $20 \%$. A few AHSS grades from the three generations together with the corresponding grading factor or ECO index (Efficiency Coefficient), i.e. the product of UTS and TEL value, are shown in Figure 2. 


\section{PRODUCTION ROUTES [2]}

Different production routes exist for DP and TRIP steels: Hot rolled, cold rolled and surface coated. Particular attention has to be paid here to the cooling strategy during the hot rolling of multi-phase steels. After formation of the austenite and the various forming steps in the roughing and finishing trains, the microstructure with the mechanical and technological properties is set by specification of the final rolling temperature (FRT) and the cooling strategy on the exit roller table with the desired coiler temperature (CT). Increasing or decreasing the cooling intensity, and hence the cooling rates, allows the transformation behavior of the microstructure and the setting of the strength to be adapted and varied within a wide range.

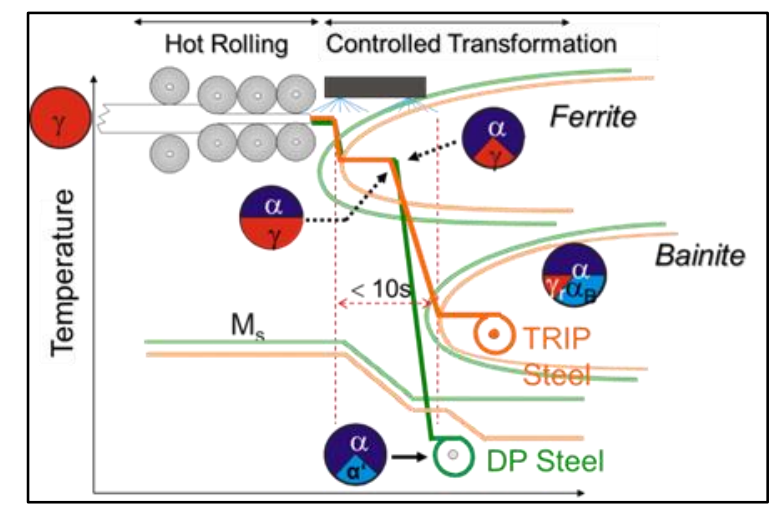

Figure 3: Production of DP and TRIP steels by controlled cooling on the exit roller table of a hot strip mill

The temperature/time behavior for the production of hot-rolled DP and TRIP steels is summarized in Figure 3. The development of the microstructure proves to be difficult, as several transformation processes are necessary while others have an unfavorable effect on the overall result. Furthermore, the sometimes limited cooling rates on the cooling line of hot strip mills have to be taken into consideration in the formation of the final microstructure. For DP steels, the cooling rates have to be low enough on the one hand to permit the transformation of the $85 \%$ austenite content into ferrite, associated with a simultaneous carbon enrichment of the austenite, and on the other hand high enough to suppress the formation of perlite and bainite and to favor the formation of martensitic at coiling temperatures of around $200^{\circ} \mathrm{C}$. For this reason, either a holding phase in the temperature range of the maximum ferrite formation is planned during the cooling process, intensive cooling is provided for or the alloying concept is adapted such that the ferrite formation is accelerated. For TRIP steels, lower cooling rates are used since the ferrite formation takes place with a delay due to the different alloying concepts, and the resulting higher carbon content forms the trigger for the subsequent bainite formation. The coiling temperature is approx. $500^{\circ} \mathrm{C}$, and the micro-structure consists of $50-60 \%$ ferrite, $25-40 \%$ bainite and $5-25$ $\%$ metastable austenite that is precipitated with a delay. The austenite is not transformed into martensite, since the enrichment with carbon during the ferrite and bainite formation shift the MS starting temperature to below room temperature.

Several possibilities exist for the production of the hot strip starting material for the manufacture of intermediates for cold rolling of multi-phase steels. 
The first possibility follows the route of producing a ferritic-perlitic material microstructure at a coiling temperature of $680^{\circ} \mathrm{C}$ to $700^{\circ} \mathrm{C}$. This material is particularly suitable for the subsequent cold rolling..

Secondly, the hot rolling process can also be carried out at a lower coiling temperature in the range of the bainite formation. Since bainite forms at around $500^{\circ} \mathrm{C}$ and represents a comparatively hard part of the microstructure, higher rolling forces are to be expected during the subsequent cold rolling. Practice has shown, however, that this process route leads to a more homogeneous and fine-grained microstructure with improved material properties in the annealed finished product.

Thirdly, a borderline route is followed by setting coiling temperatures that just avoid the phase transformation described first, but still result in low yield strength values. That makes the material easier to process on the cold rolling mill. Here the coiling temperatures on the hot strip mill lie in the range of $560^{\circ} \mathrm{C}$ to $640^{\circ} \mathrm{C}$, depending on the grade and alloy.

After cold rolling, the material undergoes heat treatment either on a continuous annealing line or hot-dip coating line. The percentages by volume of the different phases of the finished product are almost identical to those of the hot-rolled multiphase steel, but are initiated by completely different processes. The distribution of the elements and the precipitations in the individual phases and between the phases differ significantly from one another. No complete austenite formation takes place during the heat treatment of DP steels, Figure 4.

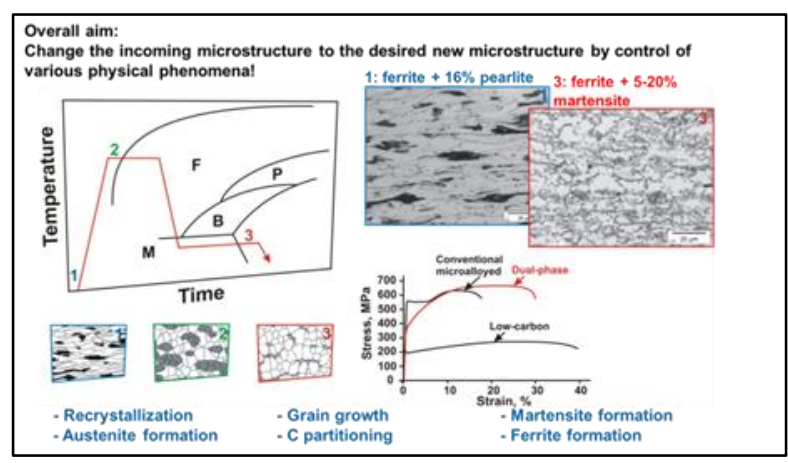

Figure 4: Production of DP steels on a continuous annealing line after cold rolling. The starting microstructure and final microstructure are shown together with corresponding temperature curves and respective intermediate states [2]

An annealing temperature slightly above the $A C 1$ transformation temperature leads to a $10-15 \%$ content of ferrite or perlite or ferrite and bainite. During intercritical annealing, these constituents are first transformed completely into austenite. During the heat treatment, a recrystallization of the cold rolled ferrite-perlite microstructure takes place that influences both the kinetics of the ferrite-austenite transformation and the size of the austenite grains. The austenite transformation starts in the perlite range with two competing processes: Growth of the previous perlite levels with high carbon content and formation of ferrite nuclei.

The second mechanism is controlled by the activation energy stored in the ferrite during cold rolling and the modification of the ferrite microstructure with different 
heating curves during annealing. After heating and a holding period in the two-phase range, the material is quenched. The austenite is transformed into martensitic during the quench cooling to room temperature. The final microstructure consists of a dispersion of martensitic islands embedded in a ferrite matrix. The ferrite content is influenced by the quenching rate, and epitaxial ferrite and/or bainite is formed. The formation of the ferrite grains during quenching is already possible from quenching rates of $50 \mathrm{~K} / \mathrm{s}$.

TRIP steels are subjected to a two-stage heat treatment with an annealing process at between 780 and $880^{\circ} \mathrm{C}$, subsequent cooling and further isothermal annealing at between 350 and $450^{\circ} \mathrm{C}$ and final cooling to room temperature.

The microstructure of the TRIP steels after intercritical annealing contains equal contents of ferrite and austenite. By contrast with the TRIP microstructure after hot forming, the ferrite is part of the microstructure during annealing and does not form only on cooling from the intercritical temperature. Cooling is interrupted for a few minutes in the bainite formation temperature range before cooling to room temperature is continued. During the second isothermal holding phase, the majority of the austenite is transformed into bainite. The final microstructure consists of 50$60 \%$ ferrite, $25-40 \%$ bainite and $5-15 \%$ austenite that is precipitated with a delay.

\section{PHASE TRANSFORMATION [2]}

The microstructure of hot-rolled dual-phase steels is heavily dependent on the thermo mechanical process conditions. On the exit roller table of the hot strip mill, the transformation of the microstructure to ferrite takes place within a few seconds. The formation of martensitic is favored by the carbon enrichment during the ferrite formation and occurs during coiling. A quantitative model of all phase transformations plays the main role for the process design and control, Figure 5. The SMS group's microstructure process monitor (MPM), for example, can be used for this. With TRIP steels, the transformation to ferrite takes place on the exit roller table and the carbide-free transformation to bainite during coiling.

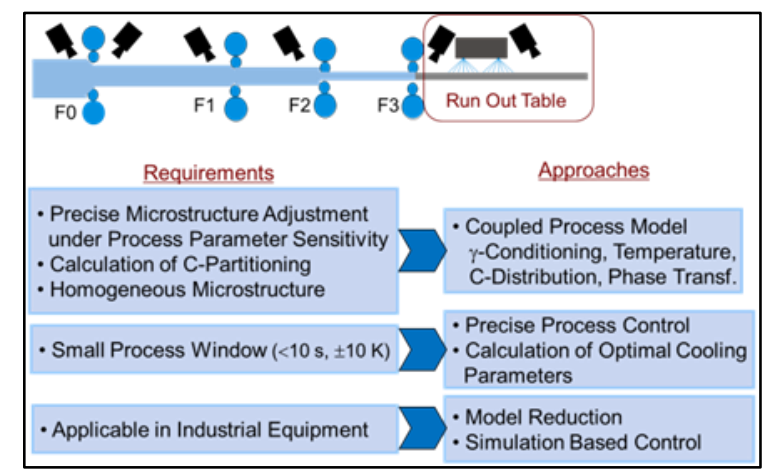

Figure 5: Modelling of the microstructure during the hot rolling of multi-phase steels [2] 


\section{THIN AND ULTRA-THIN SHEET AND METHOD FOR ITS PRODUCTION}

The method [3] describes the production and further processing of a steel grade comprising

- 0.20 to 0.45 percent by weight $C$,

- 0.50 to 2.50 percent by weight $\mathrm{Si}$,

- 2.00 to 3.50 percent by weight Mn,

- 0.005 to 0.100 percent by weight Ti and/or

- 0.005 to 0.100 percent by weight $\mathrm{Nb}$.

This steel is a third generation AHSS grade for hot and cold rolling with a minimum degree of deformation of $30 \%$. During the subsequent in the strip treatment lines of the cold rolling mill, the steel is first heated to an annealing temperature of 800 to $950^{\circ} \mathrm{C}$ and then cooled at a cooling rate of at least $5^{\circ} \mathrm{C} / \mathrm{s}$ to a temperature between 350 and $500^{\circ} \mathrm{C}$. The steel treated in this way has a microstructure with a martensitic and bainite phase of at least $80 \% \mathrm{v} / \mathrm{v}$ that is again heated to a temperature between 700 and $840^{\circ} \mathrm{C}$, quenched at cooling rates between 5 and $50^{\circ} \mathrm{C} / \mathrm{s}$ to temperatures between 350 and $500^{\circ} \mathrm{C}$ and then held at this temperature level for a period between 10 and $1800 \mathrm{~s}$. The resulting material microstructure contains 15 to $20 \% \mathrm{w} / \mathrm{w}$ ferrite, 15 to $40 \% \mathrm{w} / \mathrm{w}$ delayed precipitated austenite and $30 \% \mathrm{w} / \mathrm{w}$ or less martensitic. The delayed precipitated austenite consists of acicular crystal grains with a size of $2.0 \mu \mathrm{m}$ or smaller and a yield point of at least 2.0 or higher. The higher-strength cold-rolled steel produced in this way has a tensile strength of at least $980 \mathrm{MPa}$, high toughness properties and a low planar anisotropy.

\section{PRACTICAL APPLICATION DURING HOT AND COLD ROLLING}

The following rolling and cooling specifications therefore apply in the hot strip and cold strip mill for the production of TRIP steels.

\subsection{Production of hot rolled strip}

The final rolling temperature lies between 880 and $910^{\circ} \mathrm{C}$, depending on the grade, the coiling temperature between 580 and $640^{\circ} \mathrm{C}$. In conventional hot strip mills, the use of a coilbox, if available, is to be recommended for the setting of the final rolling temperature. Thanks to the temperature homogenisation over the starting strip length, the rolling behaviour of coilbox strips in the finishing train is stabilised [4].

If the hot strip is produced on casting and rolling plants, e.g. in CSP® (Compact Strip Production) plants, the final rolling thickness of $1 \mathrm{~mm}$ typical for cold strip can already be set during the hot forming stage [5]. This means that the use of CSP® plants allows a process stage to be saved and thus offers the possibility of resourceconserving and energy-efficient production along the whole process chain from melt shop through to the finished product after the strip treatment.

For the exit roller table, consideration has to be given to the dimensioning of the installed power for the cooling lines for both conventional hot strip mills and $\mathrm{CSP}^{\circledR}$ plants. A specific cooling volume of $35 \mathrm{~m} 3 /(\mathrm{m} 2 \cdot \mathrm{h})$ is achieved by conventional laminar cooling, $60 \mathrm{~m} 3 /(\mathrm{m} 2 \cdot \mathrm{h})$ ) by forced laminar cooling, $120 \mathrm{~m} 3 /\left(\mathrm{m}^{\wedge} 2 \cdot \mathrm{h}\right)$ by super- 
forced laminar cooling and $230 \mathrm{~m} 3 /(\mathrm{m} 2 \cdot \mathrm{h})$ by compact cooling [6]. The demanded coiling temperature can be set by a suitable arrangement of the laminar cooling systems on the exit roller table.

\subsection{Production of cold strip}

Typical final rolling thicknesses for the cold strip of TRIP steels lie in the range from 0.8 to $1 \mathrm{~mm}$. For $1 \mathrm{~mm}$ cold strip thickness, the ingoing hot strip thickness is $2.5 \mathrm{~mm}$ with a total deformation in the tandem mill of $60 \%$.

Table1: Pass schedule for the rolling of TRIP 780 in a 5 -stand tandem mill

\begin{tabular}{|l|l|l|l|l|l|}
\hline Parameter & S1 & S2 & S3 & S4 & S5 \\
\hline $\begin{array}{l}\text { Exit } \\
\text { thickness } \\
\text { [mm] }\end{array}$ & 2.07 & 1.54 & 1.21 & 1.01 & 1.00 \\
\hline $\begin{array}{l}\text { Reduction } \\
\text { [\%] }\end{array}$ & 16 & 25.4 & 21.8 & 16.3 & 0.9 \\
\hline $\begin{array}{l}\text { Speed } \\
\text { [m/min] }\end{array}$ & 371 & 497 & 634 & 759 & 777 \\
\hline $\begin{array}{l}\text { Rolling force } \\
{[\mathrm{MN}]}\end{array}$ & 17 & 21 & 20 & 18 & 17 \\
\hline $\begin{array}{l}\text { Linear load } \\
{[\mathrm{kN} / \mathrm{mm}]}\end{array}$ & 12.87 & 15.5 & 15.0 & 13.2 & 11.5 \\
\hline $\begin{array}{l}\text { Rolling } \\
\text { torque } \\
{[\mathrm{kNm}]}\end{array}$ & 75 & 192 & 149 & 100 & 41 \\
\hline
\end{tabular}

Table2: Strip tensions for the rolling of TRIP 780 in a 5-stand tandem mill

\begin{tabular}{|l|c|c|c|c|c|c|}
\hline $\begin{array}{l}\text { Para- } \\
\text { meter }\end{array}$ & Entry / S1 & S1 / S2 & S2 / S3 & S3 / S4 & S4 / S5 & S5 / Exit \\
\hline $\begin{array}{l}\text { Tension } \\
\text { [MPa] }\end{array}$ & 50 & 119 & 139 & 168 & 158 & 70 \\
\hline
\end{tabular}

A typical pass schedule for a TRIP 780 material in a 5-stand 6-high tandem mill and the corresponding strip tensions are summarized in Table 1 and 2 . The yield stress of the material is $681 \mathrm{MPa}$, the width $1395 \mathrm{~mm}$, the entry gauge into the tandem mill is $2.43 \mathrm{~mm}$ and the exit gauge from the tandem mill $1.00 \mathrm{~mm}$.

During cold rolling, the stability of the weld seam in continuous lines such as the PLTCM (Pickling Line Tandem Cold Mill) has to be taken into consideration in addition to the installed drive power on the tandem mill in order to ensure a stable rolling process at strip changes. Particular attention has to be paid there to the leading and trailing ends of the ingoing hot strip. A constant exchange of information with the upline installations is an essential precondition for successful production.

The rolling models for the pass schedule calculation are based on the elementary rolling theory of Bland, Ford and Ellis (BEF) [7] that has proven to be effective in many cold tandem mills. The actuators pivoting and roll bending of both the work rolls and the intermediate rolls, roll shifting, i.e. with $\mathrm{CVC}^{\circledR}$ plus roll grinding, ESS technology (Enhanced Shifting System) and horizontal stabilization of the backup rolls are used to set the strip passage as well as the profile and flatness of the strip. 
Table3: Chemical composition of a TRIP 780 steel

\begin{tabular}{|c|c|c|c|}
\hline Element & $\begin{array}{c}\text { Concentra- } \\
\text { tion [\%] }\end{array}$ & Element & $\begin{array}{c}\text { Concentra- } \\
\text { tion [\%] }\end{array}$ \\
\hline $\mathrm{C}$ & 0.19 & $\mathrm{~N}$ & 0.005 \\
\hline $\mathrm{Si}$ & 1.24 & $\mathrm{Mo}$ & 0.001 \\
\hline $\mathrm{Mn}$ & 1.84 & $\mathrm{Al}$ & $<0.0031$ \\
\hline $\mathrm{P}$ & 0.012 & $\mathrm{~B}$ & - \\
\hline $\mathrm{S}$ & 0.002 & $\mathrm{Nb}$ & 0.023 \\
\hline $\mathrm{Cu}$ & 0.01 & $\mathrm{Ti}$ & $<0.024$ \\
\hline $\mathrm{Cr}$ & 0.045 & & \\
\hline
\end{tabular}

The respective setpoints for the roll shifting and bending are provided by the PCFC model (Profile Contour Flatness Control) in the Level 2 system. During rolling of the strip, the actual values are recorded in the Level 1 system and any - initially manual - corrections are made on the tandem mill. The systems are adaptive and optimize the pass schedules for future rolling.

These closed-loop control systems allow very close tolerances for the cold strip target parameters to be achieved.

\section{PROCESS CONTROL DURING THE PRODUCTION OF TRIP STEELS}

This section describes the continuous process control and quality assurance for the production of TRIP 780 grades from the melt shop through to skin-passing during the strip treatment on the annealing lines of the cold rolling mill. The settings and controls described have the character of a "recipe" that has to be followed with an appropriate overall plant configuration in order to reliably achieve the desired mechanical and technological properties.

Table4: Effect of the alloying elements on the microstructure properties of a TRIP 780 steel and challenges for the process control

\begin{tabular}{|c|c|c|}
\hline Element & Influence & Task \\
\hline \multirow{4}{*}{ C } & $\gamma$-Stabilization & \multirow{2}{*}{ Welding process } \\
\hline & Determination of phase & \\
\hline & $\begin{array}{l}\text { Stability determination of the } \\
\text { delayed precipitated austenite }\end{array}$ & \multirow{2}{*}{$\begin{array}{l}\text { Reduction in notch } \\
\text { impact strength }\end{array}$} \\
\hline & Cold hardening of martensitic & \\
\hline \multirow{4}{*}{$\mathrm{Mn}$} & $\gamma$-Stabilization & \multirow{4}{*}{ Formation of carbides } \\
\hline & Ac reduction in the $\alpha$ area & \\
\hline & Hardening of ferrite & \\
\hline & Delayed formation of perlite & \\
\hline \multirow{4}{*}{$\mathrm{Si}$} & $\alpha$ - Stabilization & \multirow{4}{*}{ Surface quality } \\
\hline & Ac increase in the $\alpha$ area & \\
\hline & Delayed formation of $\mathrm{Fe}_{3} \mathrm{C}$ & \\
\hline & Hardening of ferrite & \\
\hline \multirow{2}{*}{$\mathrm{Al}$} & $\alpha-$ Stabilization & \multirow{2}{*}{$\begin{array}{c}\text { Increase in Ms starting } \\
\text { temperature }\end{array}$} \\
\hline & Delayed formation of $\mathrm{Fe}_{3} \mathrm{C}$ & \\
\hline \multirow{4}{*}{$P$} & $\alpha-$ Stabilization & \multirow{2}{*}{ Segregations } \\
\hline & $A_{c}$ increase in the $\alpha$ area & \\
\hline & Delayed precipitation of $\mathrm{Fe}_{3} \mathrm{C}$ & \multirow{6}{*}{ Notch impact strength } \\
\hline & Hardening of ferrite & \\
\hline \multirow{4}{*}{$\mathrm{Nb}$} & Grain refinement & \\
\hline & $\mathrm{C}$ transformation into $\gamma_{R}$ & \\
\hline & Delayed bainite transformation & \\
\hline & $\begin{array}{l}\text { Lowering of Ms starting } \\
\text { temperature }\end{array}$ & \\
\hline
\end{tabular}




\begin{tabular}{|c|c|c|}
\hline Element & Influence & \multirow{2}{*}{ Task } \\
\hline \multirow{2}{*}{ Cr, Mo } & $\alpha-$ Stabilization & \\
\cline { 2 - 2 } & $\begin{array}{c}\text { Delayed formation of perlite } \\
\text { and bainite }\end{array}$ & \\
\hline \multirow{2}{*}{ Ti, V } & $\alpha-$ Stabilization & \\
\cline { 2 - 2 } & Precipitation hardening & \\
\hline
\end{tabular}

\subsection{MELT SHOP}

The typical composition of TRIP 780 steel is summarized in Table 3.

The influencing mechanisms of the elements and the resulting challenges for the further processing along the process chain are shown in Table 4.

\subsection{HOT STRIP MILL}

The temperature settings for the strip are summarized in Table 5.

Table5: TRIP 780 - rolling parameters in the hot strip mill

\begin{tabular}{|c|c|}
\hline Area / section & Value $\left[{ }^{\circ} \mathrm{C}\right]$ \\
\hline Slab furnace & $1240^{\circ} \mathrm{C}$ \\
\hline Entry to finishing mill & $1050^{\circ} \mathrm{C}$ \\
\hline Exit from finishing mill WET I & $850^{\circ} \mathrm{C}$ \\
\hline Exit from finishing mill WET II & $910^{\circ} \mathrm{C}$ \\
\hline Upcoiler HT I & $650^{\circ} \mathrm{C}$ \\
\hline Upcoiler HT II & $580^{\circ} \mathrm{C}$ \\
\hline
\end{tabular}

\subsection{TANDEM MILL}

The pass schedule for the rolling of a TRIP 780 steel on a 5-stand 6-high tandem mill are summarized in Tables 1 and 2.

Table6: TRIP 780 -parameters in the annealing line

\begin{tabular}{|c|c|c|}
\hline \multicolumn{3}{|l|}{ Strip cleaning unit } \\
\hline \multirow{2}{*}{ Alkaline strip treatment } & Temperature & $70^{\circ} \mathrm{C}$ \\
\hline & Conductivity & $45 \mathrm{mS} / \mathrm{cm}$ \\
\hline \multirow{2}{*}{ Electrolytic strip treatment } & Temperature & $70^{\circ} \mathrm{C}$ \\
\hline & Conductivity & $80 \mathrm{mS} / \mathrm{cm}$ \\
\hline Brush cleaning system & Temperature & $70^{\circ} \mathrm{C}$ \\
\hline Water flushing & Temperature & $70^{\circ} \mathrm{C}$ \\
\hline Strip drying system & Temperature & $110^{\circ} \mathrm{C}$ \\
\hline \multicolumn{3}{|l|}{ Annealing furnace } \\
\hline Preheating zone & T strip & Full capacity \\
\hline Heating zone & T strip & $850^{\circ} \mathrm{C}$ \\
\hline Soaking zone & T strip & $850^{\circ} \mathrm{C}$ \\
\hline Entry to rapid-cooling zone & T strip & $750^{\circ} \mathrm{C}$ \\
\hline Exit from rapid-cooling zone & T strip & $\begin{array}{l}430^{\circ} \mathrm{C} \\
\text { Cooling rate } \\
>80 \mathrm{~K} / \mathrm{s}\end{array}$ \\
\hline Exit from overaging zone & T strip & $370^{\circ} \mathrm{C}$ \\
\hline Furnace outlet & T strip & $100^{\circ} \mathrm{C}$ \\
\hline \multirow[t]{2}{*}{ Skin pass mill } & $\begin{array}{l}\text { Strip } \\
\text { elongation }\end{array}$ & $\begin{array}{l}0.6 \% \text { with narrow } \\
\text { work roll diameters } \\
\text { and strip elongation } \\
\text { control }\end{array}$ \\
\hline & $\begin{array}{l}\text { Bending } \\
\text { force }\end{array}$ & $\begin{array}{l}\text { Reduced during } \\
\text { passage of the } \\
\text { weld seam }\end{array}$ \\
\hline
\end{tabular}


During cold rolling, practically the whole elastic (deformation) energy is converted into heat and only around $1 \%$ is absorbed by the material. This small percentage forms the trigger for the transformation processes during the subsequent strip treatment in the annealing furnace of the cold rolling mill. During cold rolling, the ferrite grains are elongated and oriented in rolling direction, accompanied by an increase in the grain boundary surface.

\subsection{CONTINUOUS ANNEALING LINE}

The parameters for the annealing furnace in the continuous annealing line are shown in Table 6. The continuous annealing line consists of the cleaning section for the fullhard cold strip in the inlet section, the annealing furnace and the skin pass stand.

\subsection{MECHANICAL AND TECHNOLOGICAL PROPERTIES}

The mechanical and technological properties of the cold-rolled and annealed fine sheet conform to DIN EN 10268 and are summarized in Table 7.

Table7: Properties of the steel grade TRIP 780 (DIN EN 10268)

\begin{tabular}{|l|l|}
\hline Parameter & Value \\
\hline Yield point & $450 \mathrm{MPa}-570 \mathrm{MPa}$ \\
\hline Tensile strength & $\geq 780 \mathrm{MPa}$ \\
\hline $\mathrm{A}_{80}$ & $\geq 21 \%$ \\
\hline $\mathrm{n}_{90}(\mathrm{~min})$ & 0.16 \\
\hline $\mathrm{BH}_{2}$ & $\geq 40 \mathrm{MPa}$ \\
\hline
\end{tabular}

\section{CONCLUSION}

This paper presents a two year development in a steel plant to establish production of AHSS grades. In general on other plants the described process chain can be adapted, but some processing parameters may be adjusted to existing equipment and customer demands.

\section{BIBLIOGRAPHY}

[1] Bleck, W. (publisher): Werkstoffkunde Stahl für Studium und Praxis. InstitutfürEisenhüttenkunde, RWTH Aachen, 5th Edition 2014.

[2] Bleck, W., et al.: Microstructure development in hot rolled advanced high strength steels. Proceedings, Rolling 2013, 10 to 12 June 2013, Venice, Italy.

[3] JFE Steel Corporation: High-Strength, Cold-Rolled, Thin Steel Sheet and Method for Manufacturing Same. W0 patent application, publicationdate: 25.08.2016.

[4] Degner, M.: Moderne Warmbandproduktion - Prozesstechnologie und Anlagentechnik. 2012 Verlag Stahleisen $\mathrm{GmbH}$, Düsseldorf.

[5] Rosenthal, D., et al.: Stahl und Eisen 129 (2009), Volume 11, p. 73-89.

[6] Sprock, A.; Hassel, C.; Krämer, S.: The influence of an enhanced run out table cooling on the microstructure, mechanical properties and alloy savings. Proceedings, AISTech Conference May 16, 2016 - May 19, 2016, Pittsburgh, PA, USA.

[7] Degner, M., Palkowski, H.: Fit for hot and cold rolling of strips - Basics and Exercises. IMP InterMediaPartners GmbH. Wuppertal, 2016. 